TechnoLEARN: An International Journal of Educational Technology

TechnoLEARN: 10(1\&2): 39-48, June \& December 2020

DOI: $10.30954 / 2231-4105.02 .2020 .6$

(O2020 New Delhi Publishers. All rights reserved

\title{
Information System and Its Types: Emphasizing Territory, Establishments and Domain Specific
}

\author{
P.K. Paul ${ }^{1}$, P.S. Aithal ${ }^{2}$, K.S. Tiwary ${ }^{3}$, R. Saavedra ${ }^{4}$, R.R. Sinha ${ }^{5}$ and \\ B. Aremu ${ }^{6}$
}

${ }^{1}$ Executive Director, MCIS, Department of CIS, Information Scientist (Offg.), Raiganj University, India, Asia

${ }^{2}$ Vice Chancellor, Srinivas University, Karnataka, India, Asia

${ }^{3}$ Dean (Science \& Management), Raiganj University, India, Asia

${ }^{4}$ Director \& Chair, International Programs, Azteca University, México, North America

${ }^{5}$ Pro Vice Chancellor (Asian Region), Commonwealth Vocational University, Tonga, Oceania

${ }^{6}$ Vice Chancellor, Crown University, Intl. Chartered Inc. (CUICI) Argentina Campus, South America

"Corresponding author: pkpaul.infotech@gmail.com

\begin{abstract}
Information and similar facets such as Data, Content, and Knowledge are also important in almost all types of organizations and institutions. There are specific divisions and units in the organization in the current age with a special focus on Information Technology. System consists of interrelated and connected various parts and objects. It can also be considered as a combination of the tools or some sub systems. In Information Systems different tools, components, and subsystems are connected to the information related activities. Information Systems can be treated as an electronic system responsible for information management in different kinds of organizations and institutions. An Information System can be technological or manual viz. deals with Computational information activities and also Manual Information activities. Information Systems in the context of the organization and with the view of IT and Technologies can be Executive Information Systems, Decision Support Systems, etc. However, these can be considered as traditional types of information systems. Information Systems further can be classified based on other criteria. This paper is a theoretical one and discusses regarding the information systems with the foundation, basic types, emerging types, etc.
\end{abstract}

Keywords: Information Systems, Digitalization, Executive Information Systems, MIS, Information Infrastructure

How to cite this article: Paul, P.K., Aithal, P.S., Tiwary, K.S., Saavedra, R., Sinha, R.R. and Aremu, B. (2020). Information System and Its Types: Emphasizing Territory, Establishments and Domain Specific. TechnoLearn: An International Journal of Educational Technology, 10(1\&2): 39-48. 
P Paul et al.

The term 'system' comes from a Latin word Systema; it is the combination of the parts, subsystems, or interrelated entities. System can be concentrated on different areas viz. environment, natural systems, structure, health, Geospatial, etc. [1], [13], [20]. The study of systems theory and studies on any part viz. natural systems or human systems, open or close system, system process and system can be called as System. System is associated and applied in many areas such as Computing, Information Science, Engineering, Human Anatomy, Medicine, Logical Systems, Social System, Energy System, Mechanics, etc. [2]. Information Systems in respect of computational systems can be composed of the Software, Hardware, Data, Procedure, People, and Feedback.

Information Systems take the help of different technologies and subsystems, viz.

* Data warehousing,

Enterprise Systems,

* Geographic Information Systems,

* Global Information Systems, etc.

Information System in other words in the context of study and research area treated as IT applications in business, management and commerce and other areas. The concept of Information Systems varies from organization to organization and sectors/ areas.

\section{Objective}

The current paper entitled 'Information Systems and Its Types: Based on Territory, Establishments and Domain Specific deals with the following aim and objectives-

* To learn about the Systems with its application/ influence areas in a brief manner.

- To know about the traditional aspects of Information Systems with emerging thoughts.

* To get an idea of emerging components in Information Systems.

* To find out the traditional types of Information Systems in a brief manner.

To learn about the Information Systems based on territory or area, locality, or periphery.

To know about the domain or subject based Information Systems with proper example.

\section{Information Systems with Types}

Information System consists of the information and various kind of components which helps in information processing and management. It is the process, systems on information related activities viz. collection, selection, processing, management, delivery. Further various techniques and technologies are also important such as Database Technology, Web Technology, Network Technology, Software Technology, Multimedia Technology and others and these are 
Information System and Its Types: Emphasizing Territory, Establishments and Domain Specific $\mathcal{P}$

important in process of developing information systems including repositories [7], [15], [16] . There are different ways in the classification of the Information Systems, viz (refer Fig. 1 also) -

Based on Tools and Procedure;

Based on Traditional and Classical Context;

Based on Establishments and Management;

Based on Mission and Specific Target;

Based on Periphery, Reach and Territorial Jurisdiction;

Based on Tools and Procedure.

Based on tools and technologies Information Systems can be classified into two Manual Information Systems and Technology Oriented Information Systems.

Manual or Traditional Information Systems are those which are managed on the basis of general and non-computing based tools and accessories such as manual sheets, file, Indexing, catalogues, document register, ledger, and so on. However, manual systems are time consuming and, in the future, it may create lots of problems [21].

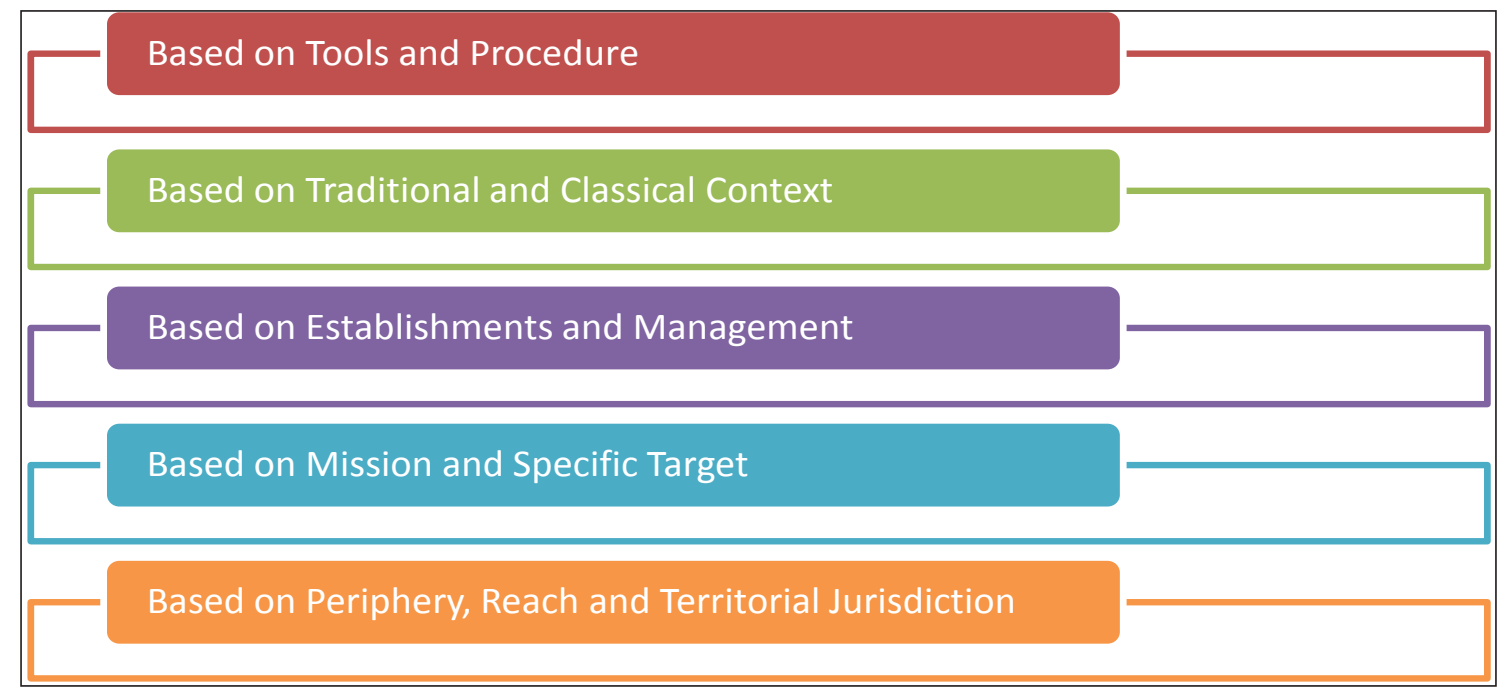

Fig. 1: Information Systems: Broad Category

Technology oriented Information Systems can be managed and run with intelligent tools and systems. It is also called as computer information using computer technology with the core components of the computer and IT tools viz.-

Hardware- such as monitor, CPU, printer and keyboard and all other components which are helpful in data and information. 
P Paul et al.

Software- are the set of programs which allow the hardware to process the data and information.

* Databases- It holds various files or tables, contents which are related and stored in a particular place.

* Networks- It is connecting systems of diverse devices that help in communications and distributes resources.

* Procedures- These are the process of gathering and delivery of information and produce the preferred output.

Apart from the above in Technology Oriented Information Systems also need to lie on Information security, multimedia systems,etc [3] [18], [21].

\section{Based on Traditional and Classical Context}

Traditionally Information Systems are considered as a process of computation of the information with the help of core technologies and proper systems viz.-

* Transaction Processing Systems.

Management Information Systems.

* Decision Support Systems.

* Executive Information Systems etc.

Here in this scenario, the Executive Information Systems consider at the highest and Transaction Processing System at the lower level in the structure.

\section{Based on Establishments and Management}

Information Systems and Networks can also be classified based in established and management or governance also and these include-

\section{Government Information Systems}

Government Information Systems are funded, managed and run by the government; these are also called as Public Information Systems. Government Information Systems are basically controlled by the concerned Government and partially their affiliated other organizations, if required. Government Information Systems are normally funded and managed by the governments and some time by the central government [8], [11]. Public Information Systems have following characteristics-

These types of Information Systems are run and funded by respective governments or a combination of some of the province or state government. 
These types of Information Systems can connect countrywide with connecting organs.

These are controlled and funded by the Government.

National Information Systems for science and technology (NISSAT), INFONET consortium of UGC are prime examples for Government Information Systems in India.

\section{Private Information Systems}

Information Systems are directly managed, funded and controlled by private organizations and institutions. Such Information Systems can be established under any society / Trust or NGO. Further, this can be run by profit making organizations as well [6], [20].

\section{Public Private (PPP) ISN}

The combination of Public Information Systems and Private Information System can help in reaching or establishing Public Private Information Systems; which are based on Public Private Partnership Model.

\section{Based on Domain and Subjects}

Information Systems may be also established or formed on a specific subject or discipline. The main aim and objective of this kind of Information Systems include the collection, selection, organization, and dissemination of information. This type of Information Systems can be established on a specific micro subject or it may be a subject or on a domain or field. Organizing and involvement of this kind of Information Systems can have a territory as a national or regional.

This type of Information System is capable of the development of information repositories and other activities. Here modern information handling tools and techniques are used. Further this kind of Information Systems helpful in supports for implementing national policy on specific subjects. Here technological infrastructure plays a leading role in developing in subjects or disciplines [22].

\section{Based on Mission and Specific Target}

Information System when dedicated in collect, select, organize and deliver information for some specific purpose aim or objective, thereafter such Information System can be called as Mission or Subject Specific Information System. These are also called as Object Oriented Information Systems and Networks (OOISN) and today many countries are giving thrust and importance in the establishment of the mission oriented. The mission may be on a special issue or subject or discipline centric viz. COVID, Malaria, health or transportation or AIDS, and so on [5], [10]. 
P Paul et al.

Information Systems on health systems.

Information Systems on travel and transportation.

* Information Systems may be on HIV/AIDS or any sensitive diseases.

* Information Systems may be on a specific community for their development like the Toto community, and so on.

* Information Systems may be on railway systems.

* Information Systems may be on weather control.

These types of Information Systems can be National or International or State/Local level or maybe Government or Private in nature. Normally these Information Systems are computational in Nature but it can manual as well. Information Systems can be therefore established on Malaria, or health or transportation or HIV, AIDS. Information Systems may be on a specific community topic viz. Information Systems may be on railway systems, Information Systems may be on weather control [9], [12].

\section{Based on Periphery, Reach and Territorial Jurisdiction}

Information Systems can also be established based on the periphery, reach, or territorial jurisdiction. This is simply such kind of Information Systems which are based on geographical boundaries. Based on size it is normally classified and depending upon country and context it is also called as Information Systems and Network or simply Information Network. Based on reach therefore it can be-

* International Level;

National Level;

State Level;

Local Level.

\section{International Information Systems}

Information Systems which are connected or established within a group of countries, or having concentration more than one country is called International Information Systems. The periphery of information dealing activity is larger than National Information Systems. These kinds of Information Systems even may not be established or connected with many countries but may have international users. There are many similar Information Systems established worldwide viz. -

UNISIST (i.e. World Information Systems for Science and Technology).

MEDLARS (i.e. Medical Literature Analysis Retrieval Systems). 
Information System and Its Types: Emphasizing Territory, Establishments and Domain Specific . P

INSPEC (i.e. International Information Services for Physics and Engineering Communities).

AGRIS (i.e. International Information Systems for Agricultural Sciences and Technology).

- INIS (i.e. International Nuclear Information Systems).

This type of International Information Systems can also be established on a particular mission or object based viz. Air Information Systems in an International Airport (Refer Fig. 2).

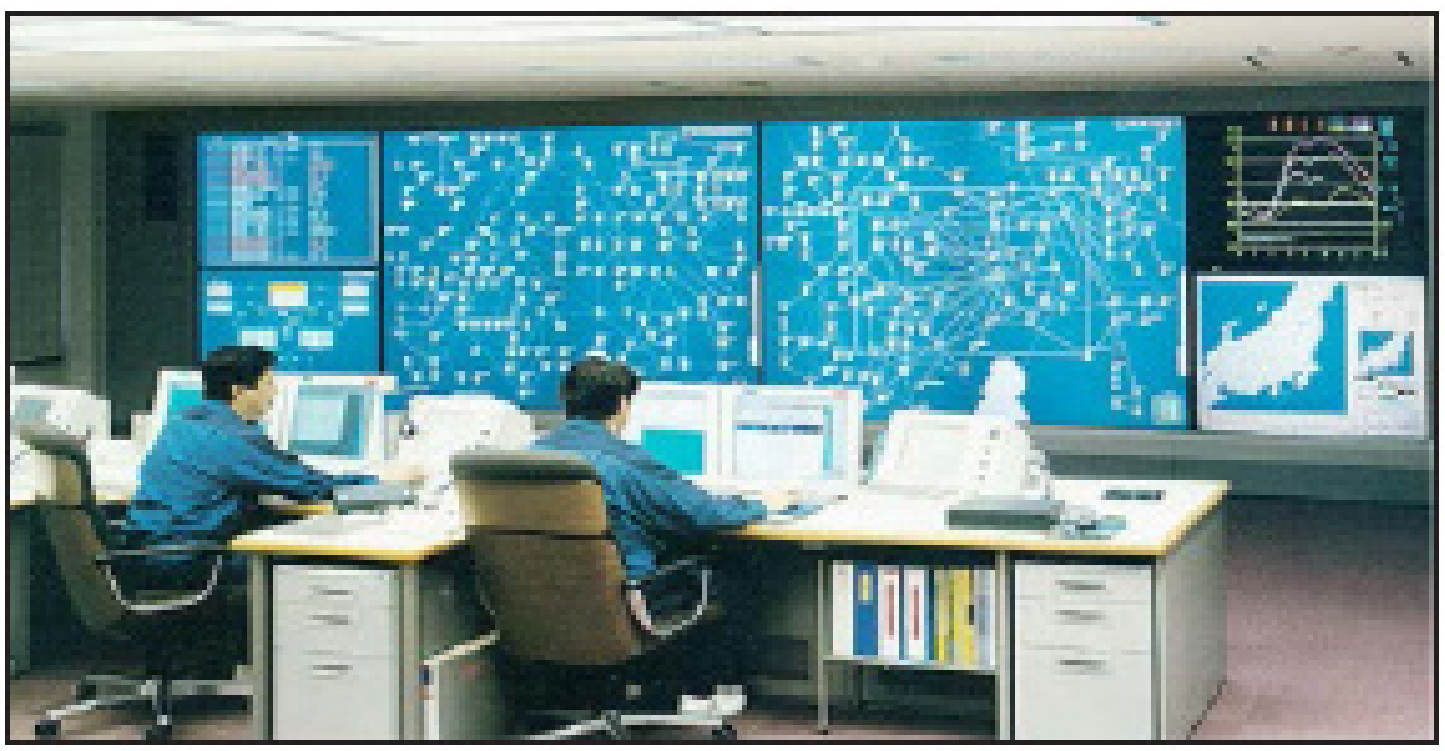

Fig. 2: Air Information Systems in an International Airport

\section{National Information Systems-}

The National Information Systems basically established, governed within a country. This kind of Information Systems is normally spread all over the country and mainly connected with other State or Local Information Systems or sometimes small Information Centers [4], [14],[17]. Even there are many information facilitating like-

* Documentation works;

Information analysis centre;

* Data centre;

Document delivery systems, and so on can also consider and make Information Systems.

National Information Systems are connected by cables or wireless devices with small information centers in any state/province. In India, many Information Systems have been viz- 
\%

NISSAT (i.e. National Information Systems for Science and Technology).

NIC (i.e. National Information centre).

* NICNET (i.e. National Information centre Networks).

ERNET (i.e. Education and Research Networks).

\section{State Information Networks}

Information Systems if established in a specific state or province then the establishment is called State Information Systems and sometimes also called as State Information Networks. In some of the countries, it is also called as Province Information Systems or Networks. In certain context, it is called Regional Information Systems and Networks. Such Information Systems basically deals with less information overload than other Information Systems i.e. International and National Information Systems or Networks. This type of Information Systems is also established in the district and combines then into a state one [4],[19]. Further in some mission oriented Information Systems building Block Level and District level Information Systems also play an important role. All of these establishments are connected via a wired or wireless way. Some of the popular Information Systems in this category are as follows-

Regional National Information Centre, Kolkata.

* NISSAT-Any Kolkata.

\section{Local Information Systems}

Local Information Systems are basically established and operated from the District or different geographical locations of the state or province. These are also called as Information Systems and Networks (ISN).

This kind of Information System is dedicated to the collection of traditional information Retrieval and storage system and sometimes plays as an Information centre. This type of Information Systems depending upon nature may be different types, viz.

* Local Culture Specific.

* Specific to the Community Services.

* Locally Mission Focused (viz. HIV/AIDS), etc.

These are the focused Information Systems dedicated to the International, National, Continental or Local level territory and helps in information development and richness [8], [11].

\section{CONCLUSION}

In the Computational context, Information Systems are normally considered as important with the collection, preservation and delivery of information of a different kind. Further many 
Information Systems dedicated to the organizational support only viz. Executive Information Systems, Decision Support Systems, etc. Technologies such as Cloud Computing, Big Data, Data Analytics, Human Computer Interaction, Usability Engineering, AI and Robotics, etc are important in developing Information Systems. Proper efforts in Information Systems can help to make a developed information base and especially healthy organizations and institutions. Territory based Information Systems are important and valuable in developing healthy information systems and complete information infrastructure in many contexts.

\section{REFERENCES}

1. Adamuthe, A.C., Salunkhe, V.D., Patil, S.H. and Thampi, G.T. 2015. Cloud Computing-A market Perspective and Research Directions. International Journal of Information Technology and Computer Science (IJITCS), 7(10): 42-53.

2. Aithal, P.S. 2016. Review on Various Ideal System Models Used to Improve the Characteristics of Practical Systems. International Journal of Applied and Advanced Scientific Research, 1(1): 47-56.

3. Al-Mamary, Y.H., Shamsuddin, A. and Abdul Hamid, N.A. 2014. The meaning of management information systems and its role in telecommunication companies in Yemen. American Journal of Software Engineering, 2(2): 22-25.

4. Arch-int, S. and Batanov, D.N. 2003. Development of industrial information systems on the Web using business components. Computers in Industry, 50(2): 231-250.

5. Brock, F.J. and Dhillon, G.S. 2001. Managerial information, the basics. Journal of International Information Management, 10(2): 5.

6. Cram, W.A., Brohman, K. and Gallupe, R.B. 2016. Information systems control: A review and framework for emerging information systems processes. Journal of the Association for Information Systems, 17(4): 2.

7. Ellis, C.A. and Nutt, G.J. 1980. Office information systems and computer science. ACM Computing Surveys (CSUR), 12(1): 27-60.

8. Gillingham, P. 2011. Computer-based information systems and human service organisations: Emerging problems and future possibilities. Australian Social Work, 64(3): 299-312.

9. Ghose, R. 2001. Use of information technology for community empowerment: Transforming geographic information systems into community information systems. Transactions in GIS, 5(2): 141-163.

10. Holdstock, D.A. 1998. Basics of geographic information systems (GIS). Journal of Computing in Civil Engineering, 12(1): 1-4.

11. Lee, A.S., Thomas, M. and Baskerville, R.L. 2015. Going back to basics in design science: from the information technology artifact to the information systems artifact. Information Systems Journal, 25(1): 5-21.

12. Maxwell, D. and Watkins, B. 2003. Humanitarian information systems and emergencies in the Greater Horn of Africa: logical components and logical linkages. Disasters, 27(1): 72-90.

13. McCune, J.C. 1994. Information systems get back to basics. Management Review, 83(1): 54.

14. Mingers, J.C. 1995. Information and meaning: foundations for an inter-subjective account. Information Systems Journal, 5(4): 285-306.

15. Nunamaker Jr, J.F., Chen, M. and Purdin, T.D. 1990. Systems development in information systems research. Journal of Management Information Systems, 7(3): 89-106. 
16. Paul, P.K., Dangwal, K.L. and Ghosh, M. 2013. Information Systems \& Networks (ISN): Increasing Tools and Technological Application with Special Reference to Role as an Educational Tools. International Journal of Computer Sciences and Engineering Systems, 7(2): 99-103.

17. Paul, P.K., Govindarajan, S., Chaterjee, D. and Bhatnagar, R. 2013. Information Systems and Information Science: Overview emphasizing comparative study. SIT Journal of Management, 3(1): 336-341.

18. Paul, P.K. 2013. Interactive Design: the pillar of Modern Information Systems. Abhinav National Journal of Science and Technology, 2(3): 15-22.

19. Paul, P.K. 2014. Information Systems and Different Domain, Functionalities and Types: A Conceptual Study. Pinnacle Mathematics \& Computer Science, 2(1): 01-05.

20. Paul, P.K., Kumar, K., Chatterjee, D., Ghosh, M., Shivraj, K.S. and Ganguly, J. 2015. Agricultural Problems in India requiring solution through Agricultural Information Systems: Problems and Prospects in Developing Countries. International Journal of Information Science and Computing, 2(1): 33-40.

21. Robey, D. 1981. Computer information systems and organization structure. Communications of the ACM, 24(10): 679-687.

22. Stivers, B.P. and Beard, L.H. 1987. Information systems: getting back to basics. Journal of Systems Management, 38(3): 35 . 